\title{
Dermatofitosis en gatos domésticos (Felis catus) positivos a retrovirus
}

\author{
Dermatophytosis in domestic cats (Felis catus) positive to retrovirus \\ Andrea Ruiz², Daniel A. Medina ${ }^{3}$, Liliana Maier², Pamela Thomson ${ }^{1,2,4}$
}

\section{Resumen}

El objetivo de este estudio fue aislar hongos dermatofitos desde lesiones dérmicas presentes en gatos domésticos (Felis catus) positivos a los retrovirus virus de la inmunodeficiencia felina (VIF) y virus de la leucemia felina (VLeF). Fueron estudiados 35 felinos: 9 positivos a VIF, 24 a VLeF y 2 a ambos virus, atendidos en la clínica veterinaria de la Universidad Santo Tomás de Santiago de Chile. Las muestras de pelos y escamas fueron obtenidas desde las lesiones dérmicas sospechosas de dermatofitosis, las cuales fueron analizadas mediante examen microscópico directo y cultivo para identificar a los agentes micóticos. El 68.6\% de los felinos fueron diagnosticados con dermatofitosis, siendo Microsporum canis el principal agente aislado. Los resultados indican una asociación significativa entre la presencia de dermatofitosis y el compromiso inmunológico de los pacientes.

Palabras claves: dermatofitosis; virus inmunodeficiencia felina; virus leucemia felina; Microsporum canis

\section{AbSTRaCT}

The aim of this study was to isolate dermatophyte fungi from dermal lesions present in domestic cats (Felis catus) positive to immunodeficiency virus (FIV) and feline leukemia virus (FelLeF) retrovirals. Thirty-five felines were studied: 9 positives to FIV, 24 to VLeF and 2 to both viruses, patients of the veterinary clinic of the Santo Tomás University of

${ }^{1}$ Departamento de Ingeniería Química y Bioprocesos, Escuela de Ingeniería, Pontificia Universidad Católica de Chile, Santiago, Chile

${ }^{2}$ Unidad de Microbiología, Escuela de Medicina Veterinaria, Facultad de Medicina Veterinaria y Recursos Naturales, Universidad Santo Tomás, Santiago, Chile

${ }^{3}$ Laboratorio de Biotecnología Aplicada, Escuela de Medicina Veterinaria. Universidad San Sebastián, Puerto Montt, Chile

${ }^{4}$ E-mail:pthomson@uc.cl

Recibido: 1 de octubre de 2018

Aceptado para publicación: 16 de abril de 2019 
Santiago de Chile. Hair and skin scale samples were obtained from skin lesions suspected of dermatophytosis, which were analyzed by direct microscopic examination and culture to identify mycotic agents. Results showed that $68.6 \%$ of the cats were diagnosed with dermatophytosis, Microsporum canis being the main isolated agent. The results indicate a significant association between the presence of dermatophytosis and the immunological compromise of the patients.

Key words: dermatophytosis; feline immunodeficiency virus; feline leukemia virus; Microsporum canis

\section{INTRODUCCIÓN}

La dermatofitosis es una infección micótica superficial, causada por un grupo de hongos denominados dermatofitos, de los cuales Microsporum canis es la especie más frecuente de encontrar en felinos domésticos (Frymus et al., 2013; Murmu et al., 2015; Moriello y Leutenegger, 2018). Estos hongos afectan tejidos queratinizados como el estrato córneo de la piel, pelo y uñas, produciendo una lesión alopécica de crecimiento concéntrico, con eritema descamación y prurito, tornando débiles y opacos los pelos de la periferia. Se pueden transmitir desde gatos portadores e infectados a través del contacto directo o indirecto, asociándose a factores de riesgo como hacinamiento, grupos etarios extremos e inmunosupresión (Moriello, 2014; Murmu et al., 2015).

Los virus de la inmunodeficiencia felina (VIF) y el virus de la leucemia felina (VLeF) son los retrovirus más prevalentes en gatos domésticos y otras especies de la familia Felidae. Ambos, son transmisibles por contacto directo y pueden afectar cualquier órgano o sistema. Los signos clínicos son consecuencia de infecciones oportunistas, neoplasias o mielosupresión, generando afecciones neurológicas, daños oculares y gingivoestomatitis, entre otros (Levy et al., 2006; Little et al., 2009; Bande et al., 2012; Munro et al., 2014).
Diversos autores han reportado la presencia de dermatofitosis en felinos inmunocomprometidos (Frymus et al., 2013; Murmu et al., 2015; Moriello y Leutenegger, 2018). $\mathrm{Al}$ respecto, se ha asociado la presencia de infecciones micóticas superficiales a pacientes con inmunosupresión; demostrando que gatos infectados con VIF albergan una alta diversidad de hongos en la piel y mucosas, en comparación con gatos no infectados (Sierra et al., 2000; Reche et al., 2010; Volgenest, 2017). No existe información en Chile referente a la dermatofitosis en felinos positivos a enfermedad retroviral (VIF y/o VLeF), por lo que el propósito de este trabajo fue diagnosticar dermatofitosis en felinos con lesiones dérmicas, positivos al virus de la inmunodeficiencia felina y/o virus de la leucemia felina.

\section{Materiales y Métodos}

Durante el segundo semestre de 2017 se realizó un muestreo dirigido para seleccionar 35 gatos positivos a VIF y/o VLeF con edades entre 2 y 10 años, sin distinción de raza o sexo, y con lesiones dérmicas sugerentes de dermatofitosis. Todos los felinos tenían propietario y vivían en el interior de una vivienda. Los animales fueron examinados, previo consentimiento informado en la clínica de la Escuela de Medicina Veterinaria de la Universidad Santo Tomás, en Santiago de Chile. 
Cuadro 1. Diagnóstico de dermatofitosis en gatos inmunocomprometidos, según el tipo de retrovirus identificado

\begin{tabular}{cccc}
\hline Retrovirus & $\begin{array}{c}\text { Negativos a } \\
\text { dermatofitosis } \\
\%(\mathrm{n})\end{array}$ & $\begin{array}{c}\text { Positivos a } \\
\text { dermatofitosis } \\
\%(\mathrm{n})\end{array}$ & $\begin{array}{c}\text { Total } \\
\%(\mathrm{n})\end{array}$ \\
\hline VLeF -VIF & -- & $5.7(2)$ & $5.7(2)$ \\
VLeF & $20.0(7)$ & $48.6(17)$ & $68.6(24)$ \\
VIF & $11.4(4)$ & $14.3(5)$ & $25.7(9)$ \\
\hline Total & $31.4(11)$ & $68.6(24)$ & $100(35)$ \\
\hline
\end{tabular}

Se extrajeron $2 \mathrm{ml}$ de sangre en tubos sin anticoagulante de la vena yugular de cada felino, previa depilación y desinfección de la zona. Los tubos fueron centrifugados a 13000 rpm durante 2 minutos. Los sueros resultantes fueron utilizados para la detección de anticuerpos contra VFI/VLeF, con el kit comercial Antigen Rapid VIF Ab / FelV Ag (Bionote, Corea) siguiendo las instrucciones proporcionadas por el fabricante y teniendo en cuenta las recomendaciones indicadas en la literatura (Westman et al., 2015, 2016).

Se obtuvieron pelos y escamas desde la periferia de las lesiones sugerentes de dermatofitosis de los gatos que presentaron signos clínicos como alopecia circular o irregular de crecimiento concéntrico, presencia de descamación, prurito y/o eritema asociado a pelos quebradizos y opacos (Frymus et al., 2013).

Se realizó un examen microscópico directo a partir de las muestras de pelos y escamas usando $\mathrm{KOH} \mathrm{10 \% .} \mathrm{Paralelamente,} \mathrm{las}$ muestras fueron sembradas en agar Sabouraud glucosa al 2\% (ASG) suplementado con cloranfenicol (BBL, EEUU) y Dermatophyte Test Medium (DTM). Los cultivos fueron incubados a $25^{\circ} \mathrm{C}$ por un periodo máximo de 21 días. La identificación de las especies de dermatofitos se basó en las características macroscópicas y microscópicas, utilizando la llave de clasificación de Hoog y Guarro (Hoog et al., 2001).
La asociación entre la presencia de enfermedad retroviral y la dermatofitosis se determinó a través de la prueba de Chi-cuadrado, utilizando el programa estadístico EPI Info 6.0 (Dean et al., 1991) considerando un nivel de confianza del $95 \%$.

\section{Resultados}

De los 35 felinos domésticos positivos a retrovirus incluidos en este estudio, $24(68.6 \%)$ fueron positivos a VLeF, 9 (25.7\%) a VIF y 2 a ambos virus (5.7\%). El rango etario fue entre 2 y 10 años, siendo el promedio de 3.6 años en gatos con leucemia felina, 6.9 años en gatos con inmunodeficiencia felina y 6 años en gatos positivos a ambos virus. Todos los pacientes analizados presentaron lesiones sospechosas de dermatofitosis, de los cuales el $68.6 \%$ fueron diagnosticados como positivos a esta infección (Cuadro 1). Los análisis estadísticos indican que entre los felinos estudiados existe una asociación significativa entre la presencia de dermatofitosis y la detección de VIF y/o VLeF $(p<0.05)$.

De los 24 felinos con cultivo positivo para dermatofitos, el examen microscópico directo (EMD) detectó la presencia de este tipo de hongos en 19 muestras, obteniendo una sensibilidad del $79.2 \%$, lo que ratifica la utilidad del EMD para realizar un diagnóstico rápido en caso de sospecha de esta afección 

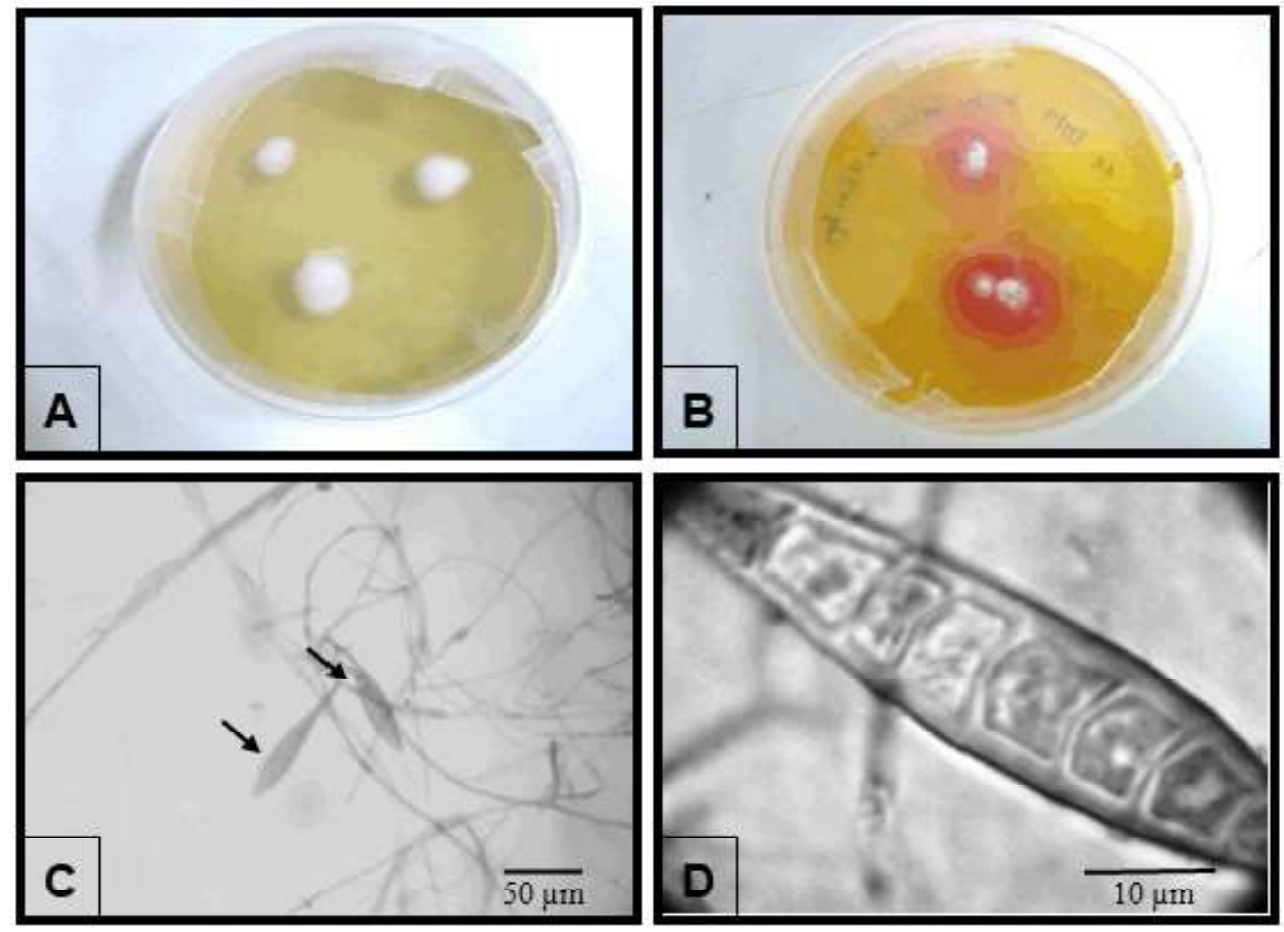

Figura 1. Visualización macroscópica y microscópica de Microsporum canis aislado desde gatos inmunocomprometidos. A: Se observan colonias resembradas de $M$. canis en placa de AGS con 4 días de desarrollo. B: Se muestran colonias resembradas en agarDTM con 2 días de desarrollo. C-D: Flechas apuntan a macroconidios de M. canis observados con $\mathrm{KOH} 10 \%$

fúngica; sin embargo, este tipo de análisis debe ser complementado con el aislamiento del hongo en cultivo microbiológico. Microsporum canis fue el dermatofito más frecuentemente aislado, presente en el $62.9 \%$ $(22 / 35)$ de las muestras, seguido de Trichophyton mentagrophytes en un 5.7\% (2/35). En agar Sabouraud-glucosa (ASG), M. canis mostró colonias planas, de color blanco a crema (Figura 1A, B). Microscópicamente, se observaron macroconidios de paredes gruesas y extremos aguzados con 5-12 células (Figura 1C, D). Por otro lado, el crecimiento de T. mentagrophytes en ASG reveló colonias planas, color crema, pulverulentas con pigmento amarillento por el envés. Microscópicamente, se observaron abundantes microconidios esféricos e hifas hialinas septadas, terminando algunas en espiral.

\section{Discusión}

Los resultados de esta investigación indican que existe una asociación entre la positividad a VIF y/o VLeF con la infección por dermatofitos en felinos domésticos, concordando con lo señalado por Reche et al. (2010), quienes mencionan que la inmunosupresión generada por una infección retroviral es un factor de riesgo para una colonización cutánea fúngica. Asimismo, otros estudios señalan una mayor tasa de portación de diversos hongos saprófitos y del género Malassezia en felinos positivos a estos virus (Sierra et al., 2000; Volgenest, 2017).

En concordancia con estos resultados, la literatura reporta que gatos mayores a seis meses de edad presentan mayor riesgo de 
seropositividad para ambos virus (Levy et al., 2006; Little et al., 2009; Munro et al., 2014). Según Bande (2012), la respuesta seropositiva al VLeF es 2.5 veces mayor en gatos jóvenes, mientras que para VIF es de 1.8 veces mayor en los gatos adultos. Así mismo, se reporta a $M$. canis como el dermatofito más frecuentemente aislado en felinos domésticos, tanto en su estado de portador como de infección (Brillowska-Dabrowska et al., 2010; Frymus et al., 2013; Moriello, 2014; Murmu et al., 2015; Moriello y Leutenegger, 2018).

Las características macro y microscópicas de las especies de hongos identificadas son concordantes con descripciones previas, donde se señala que en ASG, $M$. canis presenta colonias planas, extendidas, de color blanco a crema, con una superficie algodonosa densa que puede mostrar algunos surcos radiales. Estas suelen tener un pigmento amarillo o bien pueden presentar cepas no pigmentadas. Microscópicamente, se describen macroconidios que suelen tener forma de huso con 5-15 células, verrugosas, paredes gruesas y a menudo con un botón terminal. T. mentagrophytes, presenta colonias generalmente planas, blancas o crema, con un aspecto polvoriento, granular o aterciopelado y en el reverso se observa con pigmento amarillento o café rosado a marrón. Microscópicamente hifas hialinas, septadas y ramificadas o en espiral, abundantes microconidios esféricas o semiesféricas, que ocurren solitariamente a lo largo de la hifa o en racimos que se asemejan a racimos de uvas (Hoog et al., 2001).

Los gatos incluidos en este trabajo vivían únicamente en el interior de sus viviendas, representando una población de bajo riesgo para la colonización y transmisión micótica (López et al., 2013; Frymus et al., 2013). Aun así, mostraron un $68.6 \%$ de aislamiento de hongos dermatofitos desde lesiones sospechosas de dermatofitosis, donde la principal especie identificada fue M. canis. Estos resultados muestran la importancia de diagnosticar este tipo de infección para evitar compli- caciones con otras patologías dérmicas y disminuir su potencial transmisión a la población humana Para tales efectos, es necesario contar con métodos de detección rápidos y precisos, que permitan la identificación de especies como M. canis.

\section{Literatura Citada}

1. Bande F, Arshad SS, Hassan L, Zakaria Z, Sapian NA, Rahman NA, Alazawy A. 2012. Prevalence and risk factors of feline leukaemia virus and feline immunodeficiency virus in peninsular Malaysia. BMC Vet Res 8: 33. doi: 10.1186/1746-6148-8-33.

2. Brillowska-Dabrowska A, Wierkowska A, Lindhardt Saunte DM, Arendrup MC. 2010. Diagnostic PCR tests for Microsporum audouinii, M. canis and Trichophyton infections. Med Mycol 48: 486-490. doi: 10.3109/13693780903312454

3. Dean AG, Dean JA, Burton AH, Dicker RC. 1991. Epi Info: a generalpurpose microcomputer program for public health information systems. Am J Prev Med 7: 178-182. doi: 10.1016/ S0749-3797(18)30936-X

4. Frymus T, Gruffydd-Jones T, Pennisi MG, Addie D, Belák S, BoucrautBaralon C, Egberink H, Hartmann $\mathrm{K}$, et al. 2013. Dermatophytosis in cats: $\mathrm{ABCD}$ guidelines on prevention and management. J Feline Med Surg 15: 598604. doi: 10.1177/1098612X13489222

5. Hoog GS de, Guarro J, Gene J, Figueras MJ. 2001. Atlas of clinical fungi. USA: Amer Society for Microbiology. $1160 \mathrm{p}$.

6. Levy JK, Scott HM, Lachtara JL, Crawford PC. 2006. Seroprevalence of feline leukemia virus and feline immunodeficiency virus infection among cats in North America and risk factors for seropositivity. J Am Vet Med Assoc 228: 371-376. doi: 10.2460/javma.228.3.371 
7. Little S, Sears W, Lachtara J, Bienzle D. 2009. Seroprevalence of feline leukemia virus and feline immunodeficiency virus infection among cats in Canada. Can Vet J 50: 644-648.

8. López J, Peña A, Pérez R, Abarca K. 2013. Tenencia de mascotas en pacientes inmunocomprometidos: actualización y consideraciones veterinarias y médicas. Rev Chil Infectol 30: 52-62. doi: 10.4067/S0716-10182013000100009

9. Moriello K. 2014. Feline dermatophytosis: aspects pertinent to disease management in single and multiple cat situations. J Feline Med Surg 16: 419431. doi: $10.1177 / 1098612 X 14530215$

10. Moriello KA, Leutenegger CM. 2018. Use of a commercial qPCR assay in 52 high risk shelter cats for disease identification of dermatophytosis and mycological cure. Vet Dermatol 29: 2666. doi: $10.1111 /$ vde. 12485

11. Munro HJ, Berghuis L, Lang AS, Rogers L, Whitney H. 2014. Seroprevalence of feline immunodefi-ciency virus (FIV) and feline leukemia virus (FeLV) in shelter cats on the island of Newfoundland, Canada. Can J Vet Res 78: 140-144.

12. Murmu S, Debnath C, Pramanik AK, Mitra T, Jana S, Dey S, Banerjee S, Batabyal K. 2015. Detection and characterization of zoonotic dermatophytes from dogs and cats in and around Kolkata. Vet World 8: 1078-1082. doi: 10.14202/vetworld.2015.1078-1082
13. Reche A, Daniel AGT, Lazaro Strauss TCP, Taborda CP, Vieira Marques $S A$, Haipek K, Oliveira LJ, et al. 2010. Cutaneous mycoflora and CD4:CD8 ratio of cats infected with feline immunodeficiency virus. J Feline Med Surg 12: 355-358. doi:10.1016/ j.jfms.2009.12.017

14. Sierra P, Guillot J, Jacob H, Bussiéras; S, Chermette R. 2000. Fungal flora on cutaneous and mucosal surfaces of cats infected with feline immunodeficiency virus or feline leukemia virus. Am J Vet Res 61: 158161. doi: 10.2460/ajvr.2000.61.158.

15. Volgenest LJ. 2017. Skin as a marker of general feline health: cutaneous manifestations of infectious disease. $\mathrm{J}$ Feline Med Surg. 19(11):1149-1165. doi:10.1177/1098612X17735764.

16. Westman ME, Malik R, Hall E, Norris JM. 2016. Diagnosing feline immunodeficiency virus (FIV) infection in FIVvaccinated and FIV-unvaccinated cats using saliva. Comp Immunol Microbiol Infect Dis. 46:66-72. doi: 10.1016/ j.cimid.2016.03.006

17. Westman ME, Malik R, Hall E, Sheehy PA, Norris JM. 2015. Determining the feline immunodeficiency virus (FIV) status of FIV-vaccinated cats using point-of-care antibody kits. Comp Immunol Microbiol Infect Dis 42: 43-52. doi: 10.1016/j.cimid.2015.07.004 